\title{
Uterine sparing approaches in management of placenta accreta: a summarized review
}

\author{
Ali Hussein, Ahmed A. Abdelaleem, Ahmed M. Abbas*, Maher Salah
}

Department of Obstetrics and Gynecology, Woman's Health Hospital, Faculty of Medicine, Assiut University, Assiut, Egypt

Received: 03 November 2018

Accepted: 06 December 2018

*Correspondence:

Dr. Ahmed M. Abbas,

E-mail: bmr90@ hotmail.com

Copyright: () the author(s), publisher and licensee Medip Academy. This is an open-access article distributed under the terms of the Creative Commons Attribution Non-Commercial License, which permits unrestricted non-commercial use, distribution, and reproduction in any medium, provided the original work is properly cited.

\begin{abstract}
Placenta accreta is a potentially life-threatening obstetric condition that required multidisciplinary approach to management. Placenta accreta occurs in complete absence of the decidua basalis. Women with previous cesarean section delivery or placenta previa are known to be at greater risk of placenta accreta. A previous study reported that $24 \% \& 67 \%$ increase in the incidence of placenta accreta in women 1 versus 3 or more previous cesarean deliveries respectively. Antenatal diagnosis of placental invasion has the potential to improve maternal and fetal outcomes. In practice, incomplete non-separation of the placenta at delivery leads to massive obstetric hemorrhage resulting in maternal morbidities such as massive blood transfusion, DIC, injury to the bladder and intestines and the need for hysterectomy. Sonographic examination with gray scale and color doppler imaging is the recommended first line modality for diagnosis of morbidly adherent placenta. Techniques developed for conservative management are techniques developed to preserve uterus and future fertility which is crucially linked to societal status and self-esteem.
\end{abstract}

Keywords: Conservative, Hemorrhage, Maternal morbidity, Placenta accreta

\section{INTRODUCTION}

Placenta accreta is one of the most common causes of maternal morbidity and mortality nowadays. Uterine sparing approaches in management of placenta accreta are numerous. These could effectively substitute hysterectomy which is the definitive treatment of this condition in well selected cases. These are techniques developed to preserve uterus and future fertility which is crucially linked to societal status and self-esteem.

\section{Conservative management}

It is the expectant management by leaving placenta in situ for spontaneous resorption and autolysis. It consumes cutting cord close to the placenta and closure of uterus over placenta followed with or without methotrexate treatment. ${ }^{1}$ No large studies have compared methotrexate with no methotrexate in the treatment of placenta accreta, and at the present time, there are no convincing data for or against the use of Methotrexate in cases of placenta accreta. $^{2}$ Follow up is made by $\beta$-HCG level and Ultrasound or MRI.3 The time required for spontaneous resolution ranges from 4 weeks to 12 months with a mean 6 months. $^{4,5}$

Conservative method requires aggressive antibiotic therapy to combat infection and many adjuvant approaches to minimize bleeding like oxytocin, compression sutures, or intervention radiology methods like embolization. ${ }^{6}$

Although some cases succeeded, and placenta was expulsed spontaneously, the great majority had 
hysterectomy either promptly or later on due to hemorrhage or infection. Infectious complications of conservative method include septic shock, sepsis, infection, endometritis, wound infection, peritonitis, pyelonephritis, vesicouterine fistula and uterine necrosis. ${ }^{7}$ Other rare morbidities like choriocarcinoma and uterocutaneous fistula were also reported. ${ }^{4}$

Additional procedures were required in majority (65\%) of cases, including pelvic artery embolization, hypogastric artery ligation, and uterine compression sutures. Postpartum hemorrhage occurred in $(51 \%)$ and $(22 \%)$ of those patients required subsequent hysterectomy.

\section{Intervention radiology methods}

In these methods either Balloon-tipped catheters are placed in a retrograde fashion through the femoral arteries immediately before surgery and be inflated during the dissection in attempt to decrease the morbidity associated with placenta accreta or intervention radiologist is preoperatively place a femoral catheter with selective embolization of the uterine vessels at the time of delivery..$^{8,9}$

Current evidence is insufficient to make a firm recommendation on the use of balloon catheter occlusion or embolization to reduce blood loss and improve surgical outcome. Despite initial enthusiasm about the utility of balloon catheter occlusion, available data are unclear regarding its efficacy. ${ }^{10}$ In addition, some studies have reported an increased risk of vessel thrombosis/dissection, insertion site hematoma, abscess, necrosis, and pseudo aneurysms. ${ }^{11}$

\section{Local resection of placental implantation site}

Placenta accreta and placenta increta can be safely and successfully treated, in some well selected cases, by resection of the placental implantation site and repair of uterine defect.

This method provides immediate therapy, reduces blood loss and preserves fertility. Local resection seems to be associated with fewer complications within 24 hours postoperatively compared with hysterectomy or leaving the placenta in situ. ${ }^{12}$

The Triple-P procedure involves perioperative placental localization and delivery of the fetus via transverse uterine incision above the upper border of the placenta; pelvic devascularization; and placental non-separation with myometrial excision and reconstruction of the uterine wall.

It is considered a safe and effective alternative to conservative management or peripartum hysterectomy. ${ }^{13}$

The authors of Triple-P procedure reported remarkably low blood loss, ranging from 800 to $1500 \mathrm{~mL}$ per patient.
A follow up cohort study by the same group showed reduction in estimated blood loss, the need for delayed hysterectomy, and length of hospital stay when compared to leaving the placenta in situ plus arterial occlusion. ${ }^{14}$

\section{Systematic pelvic devascularization}

\section{Uterine artery ligation (UAL)}

Uterine artery ligation is crucial step for success of uterine preservation in many patients, with a total success rate of $78.9 \%$. The reported success rate varies from $80 \%$ to $96 \% .^{15}$ A new study done at Tanta University Hospitals (Egypt) which reported $100 \%$ success of double uterine artery ligation in management of PA. ${ }^{16}$

\section{Uterine and Ovarian arteries ligation}

Salvat et al. stated that stepwise procedure with progressive ligation of the uterine and ovarian arteries is a good solution with $100 \%$ success compared to bilateral ligation of the hypogastrics which provided success in only $66 \%$ of cases. ${ }^{17}$

Kelekci et al performed bilateral ligation of the 2 hypogastric arteries and utero-ovarian anastomosis branches were also ligated. ${ }^{18}$ The clamped cord was released, and hydro dissection was performed by heated saline at $37^{\circ} \mathrm{C}$. If placenta was not sufficiently dissected from the uterus, placental curettage or excision was performed. After homeostasis is secured, a balloon of 3ways $20 \mathrm{~F}$ Foley catheter was inflated by $80 \mathrm{cc}$ saline and placed into the intrauterine cavity and they reported success in 11 cases with preservation of their uteri.

On the other hand some authors reported severe complications such as gluteal necrosis, bladder necrosis, uterine gangrene and occasionally leg ischemia if external iliac artery is ligated by mistake. ${ }^{19}$

\section{COMPRESSION SUTURES}

The principle is mainly the compression of the uterine body and is basically the same for all types of compression sutures. The main differences being the figure at which the suture is applied, the numbers of longitudinal and/or transverse sutures used, and whether or not the uterine cavity is penetrated. The success rate for uterine compression sutures ranging from $68 \%$ to $100 \%$ with an overall success rate of $92 \% .^{20}$

\section{Vertical sutures}

Hwu et al. conducted a study on fourteen women with placenta previa (including one who also had placenta accreta) undergoing caesarean section had massive bleeding after removal of the placenta. In order to preserve the uterus, two parallel vertical compression sutures were placed in the lower segment to compress the anterior and posterior walls of the lower uterine segment. 
The hemorrhage from the lower segment stopped immediately after the knots were tightened. All women later resumed normal menstrual flow with no apparent complications.

This parallel vertical compression suturing technique is simple, easy and effective for controlling bleeding in women with placenta previa or accreta. The authors suggest that this technique should be tried first before other more complex procedures are Undertaken. ${ }^{21}$

Makino et al also tried compression sutures as 'double vertical compression sutures' because it has dual actions: haemostatic compression of the bleeding surface and reduced uterine blood flow. ${ }^{22}$

\section{Transverse B-lynch sutures}

Shahin et al. reported 24 of 26 women in whom homeostasis was secured with compression sutures, namely B Lynch sutures, following bilateral uterine artery ligation. The procedure is simple and less time consuming; however, two women had disseminated intra vascular coagulopathy and died shortly after admission to the intensive care unit. ${ }^{23}$

\section{Other sutures}

- Cho suture which is a haemostatic multiple square suture to approximate the anterior and posterior uterine wall. ${ }^{24}$

- Hayman suture which involved two vertical apposition sutures together with two transverse horizontal cervico-isthmic sutures. ${ }^{25}$

- Pereira suture was reported in 2005, which consisted of longitudinal and transverse sutures applied with superficial intra myometrial bites only. ${ }^{26}$

- Bhal suture which entailed two sutures instead of one, with the knots tied in the anterior-inferior margin of the lower uterine segment, without any difference in the compression effects compared to the original B-Lynch suture. ${ }^{27}$

- Modified suture: An observational study was conducted in China, among patients with placenta previa centralis (with or without placenta accreta). During surgery, a Foley catheter balloon containing 60-120 $\mathrm{mL}$ of water was used to compress the hemorrhage site and an absorbable suture was placed around the lower uterus segment to provide extra pressure on the balloon. ${ }^{28}$

Funding: No funding sources Conflict of interest: None declared

Ethical approval: Not required

\section{REFERENCES}

1. Tan CH1, Tay KH, Sheah K, Kwek K, Wong K, Tan $\mathrm{HK}$ et al. Perioperative endovascular internal iliac artery occlusion balloon placement in management of placenta accreta. AJR Am J Roentgenol 2007;189(5):1158-63.

2. Timmermans S, van Hof AC and Duvekot JJ Conservative management of abnormally invasive placentation. Obstet Gynecol Surv 2007;62(8):52939.

3. Courbière B1, Bretelle F, Porcu G, Gamerre M, Blanc B: Conservative treatment of placenta accreta. J Gynecol Obstet Biol Reprod (Paris) 2003;32(6):49554.

4. Sentilhes L, Ambroselli C, Kayem G, Provansal M, Fernandez H, Perrotin F, et al. Maternal outcome after conservative treatment of placenta accreta. Obstet Gynecol 2010;115(3):526-34.

5. Roulot A, Barranger E, Morel O, Soyer P, Hequet D Two- and three- dimensional power Doppler ultrasound in the follow-up of placenta accreta treated conservatively. J Gynecol Obstet Biol Reprod.2015;44(2):176-83.

6. Fox KA, Shamshirsaz AA, Carusi D, Secord AA, Lee P, Turan OM, et al. Conservative management of morbidly adherent placenta: Expert Review. Am J Obstet Gynecol. 2015;213(6):755-60.

7. Clausen C, Lonn L, Langhoff-Roos J. Management of placenta percreta: a review of published cases. Acta Obstet Gynecol Scand.2014; 93(2):138-43.

8. Dilauro MD, Dason S, Athreya S. Prophylactic balloon occlusion of internal iliac arteries in women with placenta accreta: Literature review and analysis. Clin Radiol.2012;67(6):515-20.

9. D'Souza DL, Kingdom JC, Amsalem H, Beecroft JR, Windrim RC, Kachura JR. Conservative Management of Invasive Placenta Using Combined Prophylactic Internal Iliac Artery Balloon Occlusion and Immediate Postoperative Uterine Artery Embolization. Can Assoc Radiol J. 2015;66(2):17984.

10. Butt K, Gagnon A and Delisle MF. Failure of methotrexate and internal iliac balloon catheterization to manage placenta percreta. Obstet Gynecol. 2002;99:981-2.

11. Bishop S1, Butler K, Monaghan S, Chan K, Murphy G, Edozien L. Multiple complications following the use of prophylactic internal iliac artery balloon catheterisation in a patient with placenta percreta. Int J Obstet Anesth. 2011;20(1):70-3.

12. Pliskow S, Dai X, Kohner A, Kapnick J. Conservative surgical management of placenta accreta: a report of 3 cases. J Reprod Med.2009; 4(10):636-8.

13. Chandraharan E. Should the Triple-P procedure be used as an alternative to peripartum hysterectomy in the surgical treatment of placenta percreta? Women's Health.2012; 8(4):351-3.

14. Teixidor Vinas M, Belli A, Arulkumaran S, Chandraharan E. Prevention of postpartum hemorrhage and hysterectomy in patients with Morbidly Adherent Placenta: A cohort study comparing outcomes before and after introduction of 
the Triple-P procedure. Ultrasound Obstet Gynecol.2015;46(3):350-5.

15. AbdRabbo SA. Stepwise uterine de vascularization: a novel technique for management of uncontrolled postpartum hemorrhage with preservation of the uterus. AJOG. 1994;171(3):694-700.

16. Shehata A, Hussein N, El-Halwagy A, El Gergawy A: Could Simple Procedures Minimize Hysterectomy in Management of Placenta Accreta? Indian J Obstet Gynaecol Res.2015;2(4): 213-7.

17. Salvat J, Schmidt MH, Guilbert M, Martino A Vascular ligation for severe obstetrical hemorrhage: review of the literature. J Gynecol Obstet Biol Reprod (Paris).2002;(7):629-39.

18. Kelekci, Emre Ekmekci, Serpil Aydogmus, et al., (2015): A Comprehensive Surgical Procedure in Conservative Management of Placenta Accreta: A Case Series. Medicine) Baltimore).2015;94(7):e529.

19. Palacios-Jaraquemada JM. Buttock Necrosis and Paraplegia after Bilateral Internal Iliac Artery Embolization for Postpartum Hemorrhage. Obstet Gynecol.2012;120(5):1210.

20. Doumouchtsis SK, Papageorghiou AT, Arulkumaran S., Systematic review of conservative management of postpartum hemorrhage: what to do when medical treatment fails. Obstet Gynecol Surv. 2007;62(8):540-7.

21. Hwu YM, Chen CP, Chen HS, Su TH. Parallel vertical compression sutures: a technique to control bleeding from placenta praevia or accreta during caesarean section. BJOG.2005;112(10):1420- 3.

22. Makino S1, Tanaka T, Yorifuji T, Koshiishi T, Sugimura M, Takeda S. Double vertical compression sutures: A novel conservative approach to managing post-partum hemorrhage due to placenta previa and atonic bleeding. Aust NZJ Obstet Gynaecol 2012;52(3):290-2.

23. Shahin AY1, Farghaly TA, Mohamed SA, Shokry M, Abd-El-Aal DE, Youssef MA. Bilateral uterine artery ligation plus B-Lynch procedure for atonic postpartum hemorrhage with placenta accreta. Int $\mathbf{J}$ Gynaecol Obstet. 2010;108 (3):187-90.

24. Cho JH, Jun HS, Lee CN. Haemostatic suturing technique for uterine bleeding during cesarean delivery. Obstet Gynecol.2000;96(1):129-31.

25. Hayman RG, Arulkumaran S, Steer PJ, Uterine compression sutures: surgical management of postpartum hemorrhage. Obstet Gynecol.2002;99(3): 502-6.

26. Pereira A1, Nunes F, Pedroso S, Saraiva J, Retto H, Meirinho M, Compressive uterine sutures to treat postpartum bleeding secondary to uterine atony. Obstet Gynecol. 2005;106(3):569-72.

27. Bhal K, Bhal N, Mulik V, Shankar L. The uterine compression suture-a valuable approach to control major hemorrhage at lower segment caesarean section. J Obstet Gynaecol.2005;25(1):10-4.

28. Zhu L, Zhang Z, Wang $\mathrm{H}$, Zhao J. Wue for hemorrhage during cesarean delivery complicated by complete placenta previa. Int J Gynaecol Obstet. 2015;129(1):26-9.

Cite this article as: Hussein A, Abdelaleem AA, Abbas AM, Salah M. Uterine sparing approaches in management of placenta accreta: a summarized review. Int J Reprod Contracept Obstet Gynecol 2019;8:349-52. 